\title{
European Space Agency: an Overview of the Legal Frame
}

\author{
Inessa Kostenko
}

\author{
Ph.D., Associate Professor, Scientific Research Institute of State Building and Local \\ Government of National Academy of Law Sciences of Ukraine (Kharkiv, Ukraine) \\ E-mail: inessakostenko2014@gmail.com \\ https://orcid.org/0000-0002-8784-5422
}

The article includes a legal analysis of the issue concerning relations in the space area. Speaking more clearly, it regards legal regulating of the European Space Agency. This article summarizes the history of the formation of the European Space Agency, provides its definition and outlines guiding principles of work and regulation in the European Space Agency. The article provides answers to such questions as: What does ESA do? Where is ESA located? Who are the staff of ESA? Who belongs to ESA? Where do ESA's funds come from? How does ESA operate? What are the main principles of work of its governing bodies? In accordance with the Convention, the Director-General of the European Space Agency is the highest official person of the European Space Agency, therefore, we pointed out the leading tasks and duties of this person, and highlighted in which way the Director-General is elected and appointed, what is his responsibility in case of non-fulfillment of his powers, etc. In addition, the basic provisions of the Convention, which contain special provisions relating to finance, are reviewed in the article. In view of this, it has been established that a leading position in financial management supports the implementation of the long-term European space policy approved by the Council. We also determined that the Agency is required to apply internationally recognized accounting standards and adhere to the principles of financial management, economy and planning effectiveness in order to effectively develop this industry. Using historical methods and methods of systematization the authors came to the conclusion that this organization will have a great future in its various aspects and manifestations. Consequently, the key issue for today is the task of improving the ESA regulation system.

Keywords: European Space Agency, European Space Research Organization, European Launch Development Organization, Procurement Regulations, Convention

Received: March 02, 2019; accepted: April 07, 2019

Advanced Space Law, Volume 3, 2019: 63-70.

https://doi.org/10.29202/asl/2019/3/5

(C) Kostenko, Inessa, 2019 


\section{Introduction}

For centuries people dreamed and fantasized about exploring space. Such fantasies were doomed to remain unfulfilled, however, until rockets had been developed with sufficient thrust to escape the pull of the Earth's gravitational field. Every day, the development of space science more and more needed the proper organization and legal regulation. History provides a comprehensive list of such organizations, but one of the largest and most influential ones should be considered in our investigation.

The European Space Agency (ESA), in the form it currently exists, was established with the 1975 ESA Convention. At that time, the European Space Research Organization (ESRO) was united with the European Launch Development Organization (ELDO). The Convention establishing the European Space Agency was signed by Ten European States on May 30, 1975 (Belgium, Denmark, France, Germany, Italy, Netherlands, Spain, Sweden, Switzerland, and the United Kingdom). At the same time, the Conference of Plenipotentiaries adopted a Final Act including ten resolutions. These made allowance for the transition from ESRO and ELDO to ESA dealt with the question of languages and gave additional weight to some of the key provisions of the Convention. Ireland signed the text on 31 December that year. In December 1978 Canada became a Cooperating State in terms of Art. XIV. 1 of the Convention. In October 1979 Austria signed an Association Agreement with the Agency. For five years, pending ratification ESA functioned 'de facto', rather than as a legally existing entity. ESA formally came into being on 30 October 1980, when France deposited its instrument of ratification and the Convention entered into force [Krige et al., 2000].

In accordance with the Convention Establishing the European Space Agency, approved by the Conference of Plenipotentiaries, held in Paris on May 30, 1975, the main objective of this Foundation is integration European national space programs into European space as quickly as possible. In other words, the purpose of the Agency is providing and promoting cooperation between the European States in space research and technologies and their space applications for the purpose of their use for scientific purposes and for systems of operational space applications: development and implementation of long-term European space policy, measures and programs in the space sector; recommending to Member States space targets; coordinating the European Space Program and national programs, as well as by gradually and fully integrating the latter into the European Space Program; through the development and implementation of an industrial policy that is consistent with its program and the recommendations of a coherent industrial policy to Member States Convention; Art. II Thus, the work of the ESA is not only to draw up a European space program, but also to implement it. ESA programs are designed to learn more about the Earth and space environment, to discover new facts about our solar system and the universe, as well as to develop satellite technologies, services, and European industries. It is also worth pointing out that ESA is closely cooperating with space organizations outside of Europe, and the ESA headquarters is in Paris. It should be noted that ESA also has sites in many European countries. Among them are: the European Astronauts Centre (EAC) in Cologne, Germany; the European Space Astronomy Centre (ESAC), in Villanueva de la Canada, Madrid, Spain; the European Space Operations Centre in Darmstadt (ESOC), Germany; the ESA centre for Earth Observation (ESRIN), in Frascati, Italy; the European Space Research and Technology Centre (ESTEC), Noordwijk, the Netherlands; the European Centre for Space Applications and Telecommunications (ECSAT), Harwell, Oxfordshire, United Kingdom; the European 
Space Security and Education Centre (ESSEC), Redu, Belgium. ESA also has liaison offices in Belgium, USA, and Russia; a launch base in French Guiana and tracking stations in various parts of the world. Each of these countries has its own rights and responsibilities. Currently, the ESA employs around 2,200 staff from all member states and includes scientists, engineers, IT professionals and administrative staff.

Speaking about the ESA, also we should highlight the main principle of work of its governing bodies. Consequently, according to the ESA's by-laws, there is the ESA Council, which is considered its governing body. The main task of the Council is to provide the basic guidelines for the development of the European Space Program. Each Member State is represented in the Council and has one vote, independent of its size or financial contribution. The ESA is headed by a Director General, whose term for election to the Board is four years. Speaking about the research sector, each individual sector has its own directorate and is directly responsible to the Director-General.

Article XI of Convention contains the special provision concerning the Council, his rights and duties. In accordance with this provision, the Council's main responsibility is approving the activities and program by the majority of all Member States, in addition, the Council should determine the level of resources provided to the Agency. In addition to the above, it is expedient to outline some of the leading responsibilities of the Council. These include: defining and outlining the framework of a specific policy that the Agency must fulfill in order to achieve the goal and implement the necessary actions; adopting special recommendations addressed to the Member States and response to these recommendations; determination of the order of priority setting of the programs; the adopting of reports on the Agency's annual work plans and the verification of the Agency's annual general budget; the adopting of the Financial Regulation, as well as some other financial arrangements of the Agency; consideration of costs related to the Agency's activities and the prioritization of the Agency's actions; verification, approval and publication of annual reports of the Agency; acceptance and the establishment of rules for the authorization of transfers of technology and products developed outside the Agency or with the assistance of the Member States beyond the territories of the Member States, taking into account the Agency's peaceful purposes, as well as the adopting of all other measures necessary for the fulfillment of the Agency's purpose under this Convention [ESA, 2010].

As already mentioned, the Director-General is appointed by the Council for a certain period in accordance with the constituent documents, in addition, the Director-General must be the chief executive officer of the Agency and its legal representative. So, let's find out what are the main responsibilities and duties of the Director General? Firstly, he must take all necessary measures that are important for the Agency's management, implementation of its programs, implementation of its policy and achievement of its purpose in accordance with the directives issued by the Council. Secondly, the Director-General has an obligation to prepare an annual report to the Council; in addition, this report must be published. The Director-General may also make his own proposals regarding the activities and programs of the Agency, as well as adjust certain measures aimed at ensuring the fulfillment of the Agency's objectives. It should be noted that, in accordance with the Convention, the Director-General of the European Space Agency is the highest official person of the European Space Agency. So, it is advisable to notice the most famous of them. Roy Gibson was the general director of ESRO, and the first Director General of ESA, who served from 1975 to 1980. The second Director General of ESA was Eric Kistagaard, the period of his managing the ESA was determined from 1980 to 1984. 
Before the start working at the ESA, Eric Kistgaard had been managing director of the Danish shipbuilding company OLS. Prof. Dr. Reimar Lüst was the third Director General of ESA, serving from 1984 until 1990. Professor Dr. Reimar Lüst joined the European Space Sciences Administration from the first days of the European Commission's Spatial Commission (COPERS).

The research career of Professor Dr. Reimar Lüst had a strong influence on the further development of science in the field of space. His discoveries had greatly influenced the knowledge of the time about the origins of our planetary system, outer space, solar physics, solar system, cosmic ray physics, plasma physics, hydrodynamics, and nuclear physics. It should be noted that the Professor was also involved in the development and launch of the first missile launchers and ESRO satellites to study the upper layers of the atmosphere and the planetary environment as a whole. All this had a significant impact on the development of space science. Jean-Marie Luton was appointed the Fourth Director General of ESA. The period of its heading ESA was from 1990 to 1997 . The development of his career in the space industry is determined since May 1987, when he had joined the French company Aerospatiale as the director of space programs, namely the Department of Strategic and Space Systems. After completing his work at Aerospatiale he was appointed CNES General Director in February 1989. Already in 1990, he has become Director General of the ESA, and in 2002 has become the chairman of the board of the company. The history of the board of the fifth director Antonio Rodo began in 1997 and lasted until 2003. During his managing in the ESA Rhodot has played a key role in many fields of science. Besides this, his person was highly regarded in cosmic communities both in Europe and in other countries.

The leading idea of his activity was active propaganda of international cooperation; as a result, such propaganda has become widely recognized. In addition, the name of Professor remains in history thanks to the support of the European dimension of space activities and the establishment of the satellite navigation system in Europe. Jean-Jacques Dorden was appointed as the sixth Director-General of ESA, who served from 2003 to 2015. While managing the ESA, Mr. Dordain chaired a long series of successful Ariane launches that performed important space research missions, such as the Rosetta Chaser Comet (2004) and space explorers Herschel and Planck (2009). An important point to be outlined is the fact that a number of key Earth observation satellites have been orbited. It provided unique and specific data for scientific communities to understand and monitor the environment, as well as climate change in the Earth. For example, GOCE (2009) was used to study the Earth's gravitational field, SMOS (2009) was used to study the soil moisture and salinity of the ocean; Cryosat (2010) was used to study floating ice in the polar oceans and ice coverings. The Proba-V (for vegetation) is a miniature satellite for displaying the growth of vegetation and vegetation throughout the planet, was launched at the launch vehicle Vega in early 2013. On July 1, 2015, Johann-Dietrich Jan Werner became the General Director of ESA. Earlier, from March 2007 to June 2015 he served as Chairman of the Executive Committee of the German Aerospace Center (DLR). [Krige; 2000].

The next issue deserves our attention concerning the financial contribution of ESA. As it is indicated in Article XIII of the Convention, each Member State shall pay the costs of the activities and program referred to the Article V. The contribution rate is based on the average national income of each Member State during the last three years for which the statistics are available. However, no Member shall be obliged to pay contributions in excess of twentyfive percent of the total amounts of the fees charged by the Council to cover these expenses. 
Taking into account any directions provided by the Council, we should notice that the DirectorGeneral may accept gifts or inheritances to the Agency, provided that they do not fall under any conditions incompatible with the Agency's objectives. With regard to cooperation, the ESA may, in accordance with the Council's decisions, cooperate with other international organizations and institutions. In addition, the ESA may co-operate with governments and institutions of non-member countries and conclude agreements with them for this purpose. It is worth pointing out that such cooperation may take the form of participation of non-member States or international organizations in one or more of the programs provided for by the article. Any dispute between two or more Member States or between any one of them and the Agency regarding the interpretation or application of this Convention or its annexes, as well as any dispute, referred to in Article XXVI of the Annex [Convention, 1975].

There is a fairly clear and strict position regarding the necessity for the full implementation of these or other commitments. For example, any Member State which fails to fulfill its obligations under this Convention has to cease to be a member of the Agency on a decision of the Council.

Annex II of Convention contains special provisions concerning the finance. Considering this issue in the aspect of the Convention, we can observe the following position of things. The Agency's financial management complies with the requirements, main tasks and objectives set out in Article II of the Convention. The leading position of financial management supports the implementation of the long-term European space policy, approved by the Council. It should be noted that the Agency has an obligation to apply internationally recognized accounting standards and adhere to the principles of financial management, economy, and planning effectiveness. In addition, they shall have an adequate level of resource management and the appropriate level of transparency, accountability, and control over the use of public funds. As regards the mobilization of Member States' resources, the principles of accessibility and equity must be implemented.

The main tasks and duties of the Director-General in the above-mentioned issue are the creation and implementation of such planning tools that are an absolute advantage in optimizing Agency's resources. First of all, this should be done to ensure a permanent consolidation of the implementation of the program, and also to prepare the appropriate and proper funding from the Member States. With regard to funding and budgets, we can observe that the Agency's annual budgets provide an annual instrument to the Member States and other actors. The necessity of this instrument is that it can gradually fulfill its long-term commitments while ensuring the continuity of the programs and measures approved by the Agency. Also, in this regard, we should note that the Director-General must establish appropriate accounting and report for the Member States and other funding entities in order to ensure transparency and the ability to track their respective funding status in relevant activities and programs.

The responsibilities of the Director-General are preparation, submitting and implementation budget projects to the Council containing requests for funding. Regarding the Agency's financial resources from the Member States, the management of them has a certain order. The first management is carried out by the Director-General. On the other hand, the accurate understanding of the Agency's cash resources should include their significance as a general treasury. Thirdly, the interest received should be credited to each Member State in accordance with the rules laid down in the Financial Rules. Another important strict duty of the DirectorGeneral in this matter is the introduction of a common system of internal control. This should be done to enable monitoring of effectiveness and achievement of goals, to assess 
efficiency and effectiveness of operations, as well as check their regularity and compliance with applicable rules and regulations. There is another rather interesting provision on which we should pay our attention, namely internationalization of national programs. What are the most important issues in this case? Consequently, each Member State shall provide to the participation of other Member States, within the Agency, any new civilian space project that it intends to carry out, either alone or in co-operation with another Member State. In addition, Member States shall monitor and make every effort to ensure that bilateral and multilateral space projects undertaken by the Member States do not undermine the scientific, economic or industrial objectives and goals of the Agency. [Convention, 1975].

And the last issue that needs to be considered within the framework of the Convention is the question concerning industrial policy. So, in a few words, we will highlight the most important facts. In implementing industrial policy, the Director-General must act in the light of the provisions of this Annex and the Council Directives. The powers and responsibilities of the Council include the review and control of industrial potential and the structure of industry within the Agency's activities [Rozin, 2017]. The issues of the general structure of industry and industrial groups are monitored; issues concerning the degree of specialization, and the ways of its achievement are established; issues of the coordination of the relevant national industrial policy; issues of interaction with any relevant industrial policy of other international bodies; the question of how to establish a relationship between production capacity and potential markets; the issue of establishing contacts with industry in order to be able to control and adopt the Agency's industrial policy where it is appropriate.

Like any intergovernmental organization, the Agency has the right to grant privileges and immunities. This is particularly the case with immunity from jurisdiction and enforcement, taking into account the provisions of Article IV of Annex I. What does it mean? The Agency spends a huge part of its annual budget through procurement. In this case, its member states have decided that economic operators should be provided with a review procedure aimed at ensuring full observance of their right to an effective remedy and a fair trial. With regard to the Procurement Review and Procurement Rules themselves, they should be consistent with internationally recognized procurement practices, which are the standard UNCITRAL Law on Government Procurement and the WTO Agreement on the extent to which they retain the specific needs required for the Agency, to the extent that they are consistent with the objectives set out in the Convention and the annexes, especially in the field of industrial policy. The procurement review procedure is set out in the ESA / REG / 001 Agency Procurement Regulation [ESA, 2010]. It should also be emphasized that the provisions contained in these Rules and in any other instructions on the placement of contracts are usually interpreted in such way as to ensure: transparency and fair and equitable treatment of all economic operators; economic and efficient use of Agency resources; the implementation of a specific industrial policy and the sharing of work between Member States.

Part II of the Procurement Regulations and their Annexes (implementing instructions) contains provisions concerning methods of Procurement. Among them are competitive and non-competitive tendering; two-stage tendering; framework agreements. In some detail, the issue of a tender should be considered. Consequently, in accordance with these provisions, an open tender is defined as an ordinary contract placement procedure, and the tender may be restricted to deliveries or services. Such supplies are usually procured by the Agency in accordance with the provisions of the international agreements concluded between the Agency and the public authorities. In addition, such restrictions may be applied to supplies or services 
which are secret or whose activities must be accompanied by special security measures in accordance with the Agency's current rules; for supplies or services of a proper nature, limiting the possibility of their purchase from a limited number of economic operators; for general purchases that do not have an impact on industrial policy, when it takes a lot of time and costs to study and evaluate a large number of tenders in order to make a proportional distribution of the cost of supplies or services to be procured.

Speaking of a limited tender, as well as the reasons and necessity of its application and the choice of cost-effective operators, it is appropriate to note that it must necessarily be recorded in the contract file. Occasionally cases occur when tenders can be canceled. For example when the Industrial Policy Committee has issued a directive or a guide to the Director-General in this regard. Or, if the costs do not exceed 100000 euros; or if the necessary supplies or services are the subject of intellectual property rights and, as a result, may be procured from only one particular source; if there is only one source of supply or services; as well as in case of extreme urgency due to compelling operational needs. Article 15 of Regulating contains provisions concerning the Framework Agreement.

Taking into account the leading definitions of this provision, the Framework Agreement should be understood as a single framework contract or a certain generalization of several framework contracts. Contracts of this type are usually concluded by the Agency with one or more contractors in order to provide supplies or services for a certain period and within the limits of this financial liability limit. If the Agency's purpose is establishment the most satisfactory solution for its purchasing needs, in order to obtain it, the Agency has the opportunity to participate in procurement through two stages of bidding. Several cases have been identified in which to do this. So, firstly, when there is an understanding that it is impossible to formulate detailed specifications for deliveries or services, also to determine their characteristics and establish where necessary contributions from economic operators. This is important for detailing and specifications for deliveries or, in the case of services, for identifying their characteristics. The second case is: when it takes part in the pre-qualification process in order to identify qualified economic operators. It should also be emphasized that in the case of purchasing actions exceeding or equaling 20,000,000 euros, if none of the recognized tenders received a total weighted estimate of more than or equal to 60 as a result of an assessment conducted in accordance with Article 39 of these Regulations but one or more accepted tenders received a total weighted rating in the range of 40 to 59; and the last one - in the case of procurement, when the IPC approved a two-stage approach to tenders in accordance with Article 21 of these Regulations.

After reviewing Article 17, we see the definition of "Best Practices for the Selection of Subcontractors by Prime Contractors in the Frame of ESA's Procurements". It is important to highlight the meaning of this provision and interpret it. So, it is concerning transparency and fairness. As well as the fairness of treatment with all economic entities, which complies with the provisions of Article 10.1 of this Regulation and are implemented throughout the period of its procurement. A consortium and contracted primary contractors to reproduce such claims on their subcontractors, for which purpose the Director-General sets a specific set of procurement requirements. Such requirements should apply to all such contracts between the Agency and the primary contractors. The requirements are considered to be "Best Practices for the Selection of Subcontractors by Prime Contractors in the Frame of ESA's Procurements" and should be approved by the Industrial Policy Committee [Procurement, 2016]. 


\section{Conclusion}

Having analyzed the leading provisions governing of the legal issues of the European Space Agency, we can conclude that ECA is Europe's gateway to the future in space and science. The main objective of the European Space Agency is to develop new opportunities, new research and new space achievements in Europe. In addition, it is important to ensure that investment in the development of space science and space continues to benefit European citizens and the world. In this aspect, its economic significance is quite clearly seen, since ESA is an international organization that coordinates the financial and intellectual resources of its members. ESA's leading task is development of the European Space Program, as well as implementation of the latest space researches in Europe and around the world, as ECA is closely cooperating with space organizations outside of Europe. Consequently, taking into account such a special and significant position of ESA, it is reasonable that the Agency's regulatory system should been constantly developed and reach the highest level.

\section{[ㅁ] References}

Convention for the establishment of a European Space Agency. The text of the Convention was approved by the Conference of Plenipotentiaries, held in Paris on 30 May 1975. The ESA Convention entered into force on 30 October 1980, 1975. https://www.riigiteataja. ee/aktilisa/2070/7201/5002/ESA_Convention.pdf

ESA Council Rules of Procedure (ESA SP-1317, December 2010, 7th edition), p.132, 2010. https://esamultimedia.esa.int/docs/LEX-L/ESA-Convention/SP-1317_EN.pdf

Krige, A. Russo and L. Sebesta. A History of the European Space Agency 1958 - 1987. Volume II The story of ESA, 1973 to 1987, 2000, p.34. http://www.esa.int/esapub/sp/ sp1235/sp1235v2web.pdf

Procurement Regulations and related Implementing Instructions. ESA/REG/001, rev. 4 Paris, 01 January 2016 Highlights of ESA rules and regulations, 2016. http://emits.sso.esa.int/ emits-doc/e_support/GCE/esa-reg-001revision4.pdf

Rozin, Vadim M. Technology as a Time Challenge: Study, Concept and Types of Technology. Philosophy and Cosmology. Volume 19, 2017. http://ispcjournal.org/journals/2017-19/ Rozin_19.pdf 